\title{
Usability Cost-Benefit Analysis: How Usability Became a Curse Word?
}

\author{
Mikko Rajanen and Netta Iivari \\ Department of Information Processing Science, University of Oulu, P.O. BOX 3000, 90014 \\ Oulu, Finland \\ mikko.rajanen@oulu.fi, netta.iivari@oulu.fi
}

\begin{abstract}
Usability is an important quality characteristic of software (SW) products and systems. Usability cost-benefit analysis models outline the potential benefits and costs of usability. This paper contrasts usability cost-benefit analysis literature with an empirical case in industrial setting, in which usability cost-benefit considerations (along with other usability activities) resulted in usability becoming a curse word. An interpretive case study was carried out in a SW development organization. Empirical analysis reveals that clearly divergent meanings and motives were attached to usability and its cost-benefit analysis in the organization. Increased sales and reduced development costs were strongly emphasized as benefits of better usability. However, very surprising meanings were attached to them both. Furthermore, the increased development costs associated with better usability were the main failure factor of the whole usability improvement effort. Implications both for theory and practice are discussed.
\end{abstract}

\section{Introduction}

This paper contrasts usability cost-benefit analysis literature with an empirical case in industrial setting, in which usability cost-benefit considerations (along with other usability activities) resulted in usability becoming a curse word. An interpretive case study [20] has been carried out in a software (SW) development organization. Empirical analysis reveals that clearly divergent meanings and motives have been attached to usability and its cost-benefit analysis in the organization.

Usability is defined as one of the main SW product and system quality attributes in the international standard ISO 9126. Usability refers to the capability of the product to be understood by, learned, used by and attractive to the user, when used under specified conditions [18]. Another widely referred to definition of usability is in standard ISO 9241-11, where usability is defined as: "the extent to which a product can be used by specified users to achieve specified goals with effectiveness, efficiency and satisfaction in a specified context of use" (see e.g. in [17]).

Usability has many potential benefits for development organizations, such as increased productivity and customer satisfaction. But even today there are quite few product development organizations reportedly having incorporated usability activities in their product development process. Bringing usability activities into the product development life cycle has been a challenge since the beginning of usability activities over fifty years ago [25]. One reason for this is that the benefits of better usability are 
not easily identified or calculated. Usability engineering has been competing for resources against other project groups, who do have objective cost-benefit data available for management review [19].

In the literature offering recommendations on how to introduce 'usability' into the development organizations, however, business perspective is emphasized. It is argued that one should take care that usability contributes to the business success of the development organizations [7], [13], [21], [22], [27]. Generally, usability is postulated as an important competitive edge in maturing SW markets [15], [24], [28]. However, it is also emphasized that one should ascertain that usability makes sense from the business perspective and is related to the achievement of key business goals [7], [13]. It is especially important to show the benefits achieved [21], [22], [27]. However, consideration of cost-benefit tradeoffs is also recommended [22], [24], [31]. Resources should be well planned and budgeted [3], [22], [24] and one should assure that usability does not increase development costs and time [7], [24].

We have carried out a detailed analysis of literature offering advice on usability cost-benefit analysis. Based on the literature review, an analytical framework for the empirical analysis has been developed and utilized in making sense of the empirical data derived from one case organization, into which usability cost-benefit analysis was introduced along with other usability activities. Existing literature made us also sensitive to the fact that very divergent meanings can be attached to usability in practice, the studies showing that it has been used only as a buzzword or as mere slogan without any proper understanding of it [1], [9], [16], [30]. Due to the assumed importance of the usability cost-benefit analysis, but also keeping in mind the risk that this term and its analyses may be used and interpreted in a multitude of different (and even conflicting) ways, this case study examines the process of meanings negotiation related to usability and its cost-benefit analysis in one case organization.

The paper is organized as follows. The next section reviews literature on usability cost-benefit analysis as a theoretical basis of our empirical analysis. The third section presents the case involved in this study and the procedures of data gathering and analysis. The following section outlines the results of our empirical examination. The final section summarizes and discloses the central themes and observations of the paper, outlines the limitations of this study, and suggests paths for future work.

\section{Usability Cost-Benefit Analysis}

There are surprisingly few published models for analyzing the costs and benefits of usability in development organizations. Most of the usability cost-benefit models analyzed in this paper were selected from the book Cost-Justifying Usability, by Bias and Mayhew [5]. This book was published in 1994, but it is still the best source of different usability cost-benefit models. The second edition of the book was published 2005, but it did not change the usability cost-benefit models [6]. The analyzed models from CostJustifying Usability were selected into this report, because they succeed in representing the variety of different views for usability cost-benefit analysis. In addition, Donahue's [11] usability cost-benefit article was included, since it is the latest published article on analyzing usability costs and benefits. Furthermore, Bevan [4] has published a usability 
cost-benefit analysis model in TRUMP-report. The model was included also for this analysis, because it has a slightly different viewpoint related to different business benefits of usability. The model estimates the potential usability benefits in four different product life cycles, while the other analyzed models do not deal as clearly with usability benefits in relation to the product life cycles.

There are many published models for calculating usability benefits, and as many ways of identifying the benefits. A business benefit is a positive return that the development organization expects to obtain as a result of an investment. There has been some discussion in publications about the potential business benefits of usability, but most of them are focused on specific case studies of usability benefits, or on the overall aspects of usability cost-benefit analysis [26].

The costs of better usability, on the other hand, can be categorized into three groups: one-time costs, recurring costs and redesign costs. One-time costs or initial costs cover, for example, the costs of establishing a laboratory for usability testing. Therefore, the cost is a one-time investment for usability. Recurring costs are, for example, the salary costs of the usability professionals employed in the usability testing laboratory. Therefore, the recurring costs are needed to actually do the usability activities. Redesign costs cover the costs of redesigning the prototypes based, for example, on the usability test results. Therefore, redesign costs apply only when prototypes are built and tested and there is an identified need for the redesign. These costs usually affect the product development project directly, whereas the one-time costs and recurring costs affect usually the usability team.

Next, we discuss in more detail these usability costs and benefits in relation to the published usability cost-benefit models.

\subsection{Existing Usability Cost-Benefit Analysis Models}

Ehrlich and Rohn [12] analyze the potential benefits of better usability from the viewpoint of vendor company, corporate customer and end user. They state that by incorporating usability activities into product development project both the company itself and its customers gain benefits from certain areas. When compared to other usability cost-benefit models analyzed in this paper, Ehrlich and Rohn present the most comprehensive discussion about different aspects of usability cost-benefits.

Ehrlich and Rohn do not clearly present an overall formula for calculating the value of usability benefits. However, according to them, the vendor company can identify benefits from three areas:

1. Increased sales

2. Reduced support costs

3. Reduced development costs

In some cases the link between better usability and increased sales can be found, but usually it can be difficult to relate the impact of better usability directly to increased sales. One way to identify the impact of usability to sales is to analyze how important role does usability have in buying decision. The cost of product support can be surprisingly high, if there is a usability problem in important product feature and the product has lots of users. Better usability has direct impact to the need of product 
support and, therefore, great savings can be made through less need for support. By focusing on better product usability and using usability techniques, the vendor company can cut development time and costs.

The corporate customer can expect benefits, when more usable product reduces time the end users need training. In addition to official training, there are also hidden costs of peer-support. End users often seek help from their expert colleagues, who therefore suffer in productivity. It is estimated that this kind of hidden support cost for every PC is between $\$ 6.000$ and $\$ 15.000$ every year [8]. End users are the final recipients of more usable product. According to Ehrlich and Rohn, increased usability can result in higher productivity, reduced learning time and greater work satisfaction for the end users. The end-users can benefit from higher productivity, when the most frequent tasks take less time.

According to Ehrlich \& Rohn, the costs of usability can be divided into initial costs and sustaining costs. They identify one-time costs and provide some example calculations of one-time costs of usability. Ehrlich \& Rohn also identify and provide some example calculations and further discussion of recurring costs.

Bevan [4] estimates the potential benefits of better usability to the organization during development, sales, use and support. The vendor can gain benefits in development, sales and support. Customer can benefit in use and support. When the system is developed for in-house use, the organization can identify benefits in development, use and support. In each category, there are a number of possible individual benefits where savings or increased revenue can be identified. The total amount of benefits from better usability can be calculated by adding all identified individual benefits together. Bevan discusses mainly usability benefits through increased sales, less need for training and increased productivity. Benefits through decreased development time are identified, but they are not discussed in detail.

Bevan does not identify one-time costs of better usability at all. Bevan identifies the recurring costs of usability, but does not provide example calculations or further discussion about calculating the recurring costs.

Karat [19] is approaching the usability benefits through cost-benefit calculation of human factors work. This viewpoint is different from the other analyzed usability cost-benefit models. There are some examples of identified potential benefits. The benefits are identified as:

1. Increased sales

2. Increased user productivity

3. Decreased personnel cost through smaller staff turnover

The development organization can gain benefits when better usability gives competitive edge and therefore increases product sales. Customer organization can gain benefits when end user productivity is increased through reduced task time and when better usability reduces staff turnover. Karat describes a usability cost-benefit analysis of three steps. In the first step, all expected costs and benefits are identified and quantified. In the second step, the costs and benefits are categorized as tangible and intangible. The intangible costs and benefits are not easily measured, so they are moved into a separate list. The third step is to determine financial value for all tangible costs and benefits. Karat also links the usability cost-benefit analysis into business cases. 
Business cases provide an objective and explicit basis for making organizational investment decisions [19].

Karat identifies one-time costs, recurring costs and prototype redesign cost of usability, but he does not provide further documentation or example calculations.

Mayhew and Mantei [23] argue that cost-benefit analysis of usability is best made by focusing the attention on the benefits that are of most interest to the audience of the analysis. The relevant benefit categories for the target audience are then selected and benefits are estimated. Examples of relevant benefit categories are given for vendor company and internal development organization. Vendor company can benefit from:

1. Increased sales

2. Decreased customer support

3. Making fewer changes in late design life cycle

4. Reduced cost of providing training

The benefits for internal development organization can be estimated from categories of increased user productivity, decreased user errors, decreased training costs, making fewer changes in late design life cycle and decreased user support. To estimate each benefit, a unit of measurement is chosen for the benefit. Then an assumption is made concerning the magnitude of the benefit for each unit of measurement. The number of units then multiplies estimated benefit per unit.

According to Mayhew \& Mantei the calculation of the costs of better usability is fairly straightforward, if the necessary usability tasks are identified. They identify one-time costs and provide some example calculations of one-time costs. Mayhew \& Mantei also identify and provide some example calculations and further discussion of the recurring costs of usability. They also identify the prototype related redesign costs and provide some example calculations of this cost factor, but there is no further documentation about calculating the redesign costs.

Donahue's [11] usability cost-benefit analysis model is based on the model of Mayhew \& Mantei. In this model, the costs and benefits of better usability are analyzed through costs for development organization and benefits for customer organization. According to Donahue, the most important aspect of usability cost-benefit analysis is calculating the savings in the development costs.

Donahue identifies one-time costs and provides some example calculations of onetime costs of usability. He also identifies recurring costs, but does not provide example calculations or further discussion about calculating the recurring costs.

\subsection{Analytic Framework for Empirical Analysis}

Table 1 summarizes the costs and benefits of usability outlined by the usability costbenefit analysis models presented above. Our focus in the empirical analysis will be on the development context, because the empirical data has been gathered solely from that context. However, also the benefits to be achieved through better usability in the use context (including both the customers making the buying decisions and the end users) are summarized in the table 1 . This is because we assumed that in the development context, one should acknowledge the benefits achievable in the use context, while motivating the usability activities in the development context. 
Table 1. Analytic framework for empirical analysis of usability costs and benefits

\begin{tabular}{lll}
\hline & Development context & Use context \\
\hline Benefits & Increased sales & Reduced training time \\
& Reduced support costs & Increased productivity \\
& Reduced development costs & $\begin{array}{l}\text { Increased (customer, user) } \\
\text { satisfaction }\end{array}$ \\
& Reduced training costs & Reduced staff turn over \\
& & - \\
Costs & One-time costs & \\
& Recurring costs &
\end{tabular}

In addition, we acknowledge that the benefits can be separated into tangible and intangible benefits [19]. However, advice for the cost-benefit analysis is offered only related to the tangible benefits. Furthermore, a noteworthy observation is that the models mostly assume that the benefits should and can be quantifiable. In all, our empirical analysis will be based on the assumed usability costs and benefits listed in table 1, acknowledging also the distinctions between tangible/intangible and quantifiable/non-quantifiable benefits mentioned above.

\section{Research Method}

This is an interpretive case study on 'usability cost-benefit analysis' in a SW development organization. Generally, in interpretive case studies the goal is to understand and to make sense of the world, not to explain in the predictive sense. In the focus are the meanings attached to the phenomenon studied. The researchers try to capture the native's point of view, to produce 'thick descriptions', and to gain thorough understandings of particular cases. Theories are used only as sensitizing devices. [10], [20].

The case organization involved in this study is a small-to-medium sized SW development company developing large scale business-to-business information systems (IS) and SW intensive products targeted at international markets. The customer organizations have their own customers, who are an important end user group of the company's products. In addition, inside the customer organization, there are different kinds of end users, who mostly are different persons than the ones who make the buying decisions. Related to the most of the company's products, the end users do not have technical background nor much training related to the use of the products.

Access to the case organization was gained through a research project that aimed at introducing usability activities into SW development organizations. The case organization participated in the research project for two years. Prior to that, the organization had very limited background in usability activities. The only activities that had been carried out in the organization were few usability tests and heuristic evaluations carried out as student work. In the company, an in-house improvement project 'Usability' was launched. The improvement work was initiated by a process assessment, in which the current state of the usability activities in the organization was evaluated. Afterwards, many different kinds of usability activities were experimented with in the organization, including customer visits, usability requirements definition workshops, 
paper prototyping, usability testing and the development of a user interface (UI) style guide. Usability cost-benefit analysis was discussed in several meetings, but no formal cost-benefit analysis was carried out.

The research material was gathered during two year's time. The material was collected while conducting the process assessment in the organization, and while supporting the Usability project. The process assessment consisted of interviews of 20 people working in different units of the organization. The assessment produced a large amount of research material, including assessment reports, interview transcripts and field notes kept by the researchers. In addition, the researchers had regularly meetings with the Usability project team and with the personnel of certain functional units of the organization. Memos from the meetings and all e-mail correspondence with the personnel have been saved for the purposes of the research. The research team also continued keeping field notes after all joint events. Furthermore, the key personnel of the Usability project were interviewed several times during the project.

Regarding data analysis, we utilized the analytic framework developed for empirical analysis (see section 2.2) as a sensitizing device. We searched for meanings attached usability and its cost-benefit analysis in the research material focusing especially on meanings attached to the usability costs and benefits - both from the viewpoint of the development and the use context - expressed in the case organization.

\section{Empirical Findings}

In this section we describe our empirical findings related to meanings attached to the usability costs and benefits expressed by the personnel of the case organization. The section reveals that regarding usability benefits, increased sales and reduced development costs were strongly emphasized, but also that very surprising meanings were attached to them both. Reduced training and support costs, on the other hand, were only mentioned. From the viewpoint of the use context, increased customer satisfaction was acknowledged. However, regarding usability costs, the costs associated with usability during the development were the main failure factor of the whole usability improvement effort. Next these issues will be discussed in more detail.

\subsection{Usability Benefits as Increased Sales and Decreased Development Costs}

Increase in sales, achievable through usability, was a very important motivating factor for the company to participate in the research project:

"The company is expecting some concrete advantages (from the improvement effort) to appear. (...) The product should be more usable, and there should appear clear savings in money and increase in sales." (Interview, usability specialist)

A noteworthy observation is that 'concrete advantages' and 'clear savings in money and increase in sales' were highlighted as fast as after one years joint effort.

'Increased sales' was assumed to be achieved through using usability as a tool to convince the customer in sales and marketing:

"ISO standard [17] aroused unexpected enthusiasm. Ed (a project manager) figures out appropriate slogans (dealing with usability) and t-shirts (with the slogans) for the company. He was delighted of the possibility to slash the demands of customers 
with the help of this authoritative standard. It is a good tool in the sales and marketing." (Field notes)

"Eric (a development manager) noticed that if the company can appeal to the standard [17] and affirm the customer that the usability capability of the organization is on a high level, the company could prove that the customer is the one who is wrong. (...) "We design our products according to the principles of this standard, so we are the ones who are right"." (Field notes)

"Customers do not know what is good for them. The company has to convince the customers that the company knows better. One way to do that is to appeal to the fact that the company participates in the university project dealing with usability issues. This might give authority to the company in relation to the customer. "(Field notes)

The marketing was eagerly expecting that their: "marketing demos with high usability will sell themselves and conquer the world" (Field notes). Improvement of the image of the company was emphasized: "Improvement of our company's image is one of the main reasons why we participate in this project" (Interview, usability specialist). Previously, the company had also acquired a quality system that was promoted in the sales and marketing, even though the quality system was not actually implemented in the development (Field notes). Therefore, there seems even to be a history of this type of 'convincing of the customer'. In all, one can conclude that usability was seen by the management as a tool for improving the image of the company and as a tool for controlling the demands made by the customers.

The reduced support and training costs were only mentioned in the company. The main functions for the customer support were "to hold the hand of the customers so that they feel better" and to "act as a bug report filter between customers and development team" (Field notes). Usability benefits were not assumed to realize significantly in the customer support. The possible benefits of better usability through reduced training costs was not seen as a very important factor either, since the company wanted to train only a limited number of contact persons, who, in turn, trained some of the end user groups whatever way they wanted to do that (Field notes).

The reduced development costs, on the other hand, were a significant selling point of usability improvement inside the organization. As already has been highlighted, the company clearly stated that they needed usability for keeping the customers away from the development process:

"Eric (a development manager) told me the basic reasons why we would participate. We need to be more convincing in the eyes of the customer. That way we could dictate some things, for example UI issues. The project would offer facts which could enable us to do that." (Interview, usability specialist)

The project managers were longing for a weapon against customers:

"Usability will be an advertising gimmick and sales argument. A powerful weapon against the customers, shortening the development time and a source of authority that allows us to write the specs as we see best - and the best way is the old way like we have always done these things." (Field notes).

"According to Ed (a project manager) usability is a nice slogan in the marketing and helpful when too demanding customer must be tamed. Usability is still not everything. Ed says that they really do not need any more new wishes or opinions from 
the users. Too much user-centered design and user involvement with several differing users' voices does not sound very inspiring." (Field notes)

The above citation reveals that the reduced development costs were associated with 'keeping the customer out of the development' instead of 'getting the requirements right and for that reason getting rid of late changes' that typically has been outlined as the factor reducing the development costs. This can be connected to the company's use of specification documents to make the customer to 'say yes':

"Susan (a developer) tests the system. She has noticed some usability problems during the tests and communicated them to the development. In the tests one is not supposed to evaluate usability. And noticed usability problems may still be ignored, if the system functions the way described in the specification. The customer has already said yes." (Field notes)

Therefore, in this company the goal is to make the customer to sign the specification document, after which the customers should not be involved with the development at all. The customers are expected to pay for each 'late change' separately after signing the specification document.

The possible benefits of better usability for the use context were not discussed much in the case organization. Generally speaking, the management, sales and development were not very interested in the benefits of better usability to the customer and the end users, but instead they maintained that "the system should look very nice and usable for the paying customer" (Field notes). In addition, "if the interests of end users and customer are conflicting, the customer wins" (Field notes).

Increased customer satisfaction was mentioned as a potential benefit of usability. Customer satisfaction had also been followed up, but not systematically. Related to the efforts of following up customer satisfaction, however, it was required that "increased customer satisfaction should have a positive effect on company's profit" (Field notes). This observation may be related to the company's noteworthy hurry to gain also clear financial indications of the benefits of usability, mentioned earlier.

\subsection{Usability Costs as Increased Development Costs}

A big problem in the case organization was that the developers questioned the practicality of usability activities. For instance Rick, a developer manager, continuously questioned the usefulness of the usability activities:

"Rick suspects whether the specification produced by the UI team through paper prototyping is finished. He doubts whether the exceptions and all the requirements are taken into account. He supposes that the specification is yet not completed." (Field notes)

"Rick again suspects the suitability of user-centered design. Last time he raised doubts about whether the requirement specifications (produced by a UI team) are complete: have all exceptions and requirements been taken into account? Now he argues that paper prototyping seems to have too many loops and users; when can you stop?" (Field notes)

In this company, "staying on the schedule" was considered as the main issue in the development project. "It would be good, if the development time was shortened 
through usability activities, but by no means can the usability work hinder the development work and delay the schedule." (Field notes)

The developers and their managers suspected that the usability activities increase the development time instead of reducing it. In addition, they viewed usability activities, altogether, as useless:

"Of the cooperation Pete (a developer) mentions that as a result something concrete and visible needs to appear. Usability activities have not resulted in that so far." (Field notes)

Financial reasons eventually led the organization to even abandon usability improvement altogether:

"When we were making the budget for this year, the question was: why spend resources on this (usability)? It costs money when people participate in this; they spend time on that. What can you get out of this? (...) This type of questioning exists and it is good, because it all comes down to money and resources. We have limited resources and must have clear arguments." (Interview, development manager)

"When compared to the costs one can raise a question that what has been received? The company has spent much more money on UI design than what was planned. (...) Eric (a development manager) says the company has moved backwards: in the beginning this (usability improvement effort) was a big thing, but now the situation is that soon nothing is done. Eric asks Rick (a development manager): has usability become a curse word?" (Field notes)

"According to Eric, Rick has decided that no user-centered design activities will be carried out in the new product development project. (...) Due to the bad reputation it currently has, the term usability will not be mentioned for a while" (Field notes)

Therefore, the costs of usability (in the sense of developers' perception of increased development costs, even though UI design costs would have realized in any case) seem to have resulted in usability becoming a curse word. Especially the recurring usability costs and the redesign costs that realized during the paper prototyping seem to have had such a serious effect on the whole usability improvement effort.

It can be argued that by introducing the concept of usability cost-benefit analysis, the costs of usability were made to appear very clearly, but the possible benefits remained too vague to really have an effect. The usability activities appeared as too costly and time consuming to the management, even though the actual UI design and redesign tasks, time and costs would have realized to a certain extent in any case (since the company's products and systems all have a UI).

The benefits of better usability were not given enough time to become visible, because the usability improvement effort was halted so quickly. The promises of future benefits through better usability were not enough to convince the management to continue the usability activities in the case organization.

\section{Concluding Discussion}

This paper contrasted usability cost-benefit analysis literature with an empirical case in industrial setting, in which usability cost-benefit considerations (along with other 
Table 2. Empirical results in relation to the analytical framework on usability cost-benefits

\begin{tabular}{ll}
\hline Usability Cost-Benefits & Empirical findings \\
\hline $\begin{array}{l}\text { Benefits for the devel- } \\
\text { opment context }\end{array}$ & $\begin{array}{l}\text { - Increased sales through use of usability as a tool in } \\
\text { sales and marketing, as a tool for convincing the cus- } \\
\text { tomer, resulting in marketing demos that sell themselves } \\
\text { and conquer the world } \\
\end{array}$ \\
$\begin{array}{ll}\text { - Reduced development costs through usability keeping } \\
\text { the customers out of the development }\end{array}$ \\
$\begin{array}{ll}\text { Benefits for the use con- } \\
\text { text }\end{array}$ & $\begin{array}{l}\text { Increased customer satisfaction that, however, needs } \\
\text { to have a positive, visible effect on company's profit }\end{array}$ \\
ment context & - Increased (recurring and redesign related) develop- \\
& ment costs (actually UI design costs that would have \\
realized in any case), usability activities condemned as & ineffective, labor intensive and time consuming
\end{tabular}

usability activities) resulted in usability becoming a curse word. Table 2 summarizes our empirical results in relation to the analytical framework that was developed based on our literature review on usability cost-benefit analysis models (see table 1).

In all, our empirical analysis revealed that divergent meanings and motives were attached to usability and its cost-benefit analysis in the case organization. Increased sales and reduced development costs were strongly emphasized as benefits of better usability. However, very surprising meanings were attached to them both. Reduced training and support costs, on the other hand, were only mentioned. From the viewpoint of the use context, increased customer satisfaction was acknowledged. However, the increased development costs associated with better usability were the main failure factor of the whole usability improvement effort.

Next we discuss the implications of the empirical results in relation to the existing usability cost-benefit analysis literature. First of all, we emphasize that usability costbenefit analysis models need to recognize more clearly that it will take time that the usability benefits are realized, and the costs will be evident much earlier. In all, time is an important issue for the development projects. The project managers may be hesitant to introduce any usability activities to their project, because they fear that those activities only consume more time, and the promised savings in the development time through less need for redesign are quite vague. The costs of usability activities are very much tangible and quantifiable, but the possible benefits are quite intangible and usually not easy to quantify reliably. Also, the cost of better usability is to be paid early in the development project, whereas the promised benefits of better usability may or may not be achieved in the distant future.

Altogether, the usability cost-benefit analysis models seem to highlight issues that are either too insignificant, too vague or solely aim at serving business needs neglecting the interests of the end user. In our empirical case, it can be argued that the usability cost-benefit models did not succeed in raising the right issues to convince the management to continue the usability improvement effort. The potential benefits of usability already acknowledged in the case organization seemed to be not enough for the management. In addition, some of the possible benefits of better usability that the 
usability cost-benefit models identify were considered as insignificant. As mentioned, reduced training and support costs were ignored in the case organization. In addition, the managers pointed out that even more insignificant issues are highlighted in these models. For example, in one of the project workshops, after a researcher presentation arguing that savings in printing costs of product manual should be counted also as a benefit from better usability, a manager from another participating company made a very critical comment that "This is peanuts. We should not spend any time discussing this issue. When I am handling project costing several millions, why should I care about saving few hundreds through having to print fewer pages for the product manual?" (Field notes). Having to print fewer pages for the product manual was raised as a possible benefit through better usability by many usability cost-benefit analysis models, but the managers in the workshop considered calculating and even discussing this benefit just a waste of time.

Regarding neglecting the interests of the user, our case shows that the management, sales and development were only interested in the paying customers and did not show interest in the end users. It can be argued that the usability cost-benefit models did not raise the right benefits so that the management, sales and development would have paid more interest to the users. One could even argue that the usability costbenefit considerations might have directed the attention solely to the paying customer and to the finances of the development organization, which, of course, also need to be considered, but which should not result in total neglect of the end user interests.

Therefore, the empirical results outlined in this paper are next contrasted with the conference theme 'social responsibility', arguing for socially responsible HCI. Actually, the results achieved within this study can be argued of being very alarming from this viewpoint. The management goals of 'taming the customer' and 'improving the image of the company' by appealing to usability can be criticized of being overtly capitalist, and even as 'misuses of usability', since in this situation one does not necessarily develop usability at all, but only uses it to convince and in the worst case to hoax the customer. The management goal of 'taming the customers' with the help of usability might even be viewed as a way of 'silencing the users', instead of 'giving them a voice' [2]. This can also be interpreted as a form of technological colonialism [2], only dressed in the gown of 'usability'. In the case, the users and the customers can be argued of being 'colonized' by appealing to usability for the sake of management goals of the development organization. It can be argued that this kind of 'misuse of usability' runs against the noble principles of $\mathrm{HCI}$ tradition, where the purpose is to understand and appreciate particularly the end users and to provide design solutions with good usability to serve them the best way possible.

Altogether, according to Spinuzzi [29], this type of capitalist orientation can be viewed as the 'realization of Scandinavians worst fears'. He refers to the Scandinavian IS research tradition (e.g. [14]) that has advocated workplace democracy and union involvement in the development of computer systems. The tradition relied on the notion of conflict between capital and labor, and positioned itself strongly on the side of the labor against the 'oppressors'. One could argue that also 'usability people' (and usability cost-benefit analysis models) should be positioned on the side of 'the user', not 'the manager', i.e. they should aim at ensuring that the usability efforts are beneficial especially for the user, even though hopefully also for the other stakeholder groups. In all, regarding research on usability cost-benefit analysis, we argue that the researchers 
should carefully consider the different kinds of interpretations of usability costs and benefits, and particularly the different kinds of uses of their analysis revealed in this paper. In addition, we argue that the research community should take some responsibility of these uses and interpretations, or at least consider how to advocate more 'appropriate' uses and interpretations.

Regarding limitations of this study, the results are based on the analysis of only one case. Clearly more empirical research, employing a larger amount of cases, is needed to understand this phenomenon in depth. However, by focusing on only one case we were able to analyze this particular case and the interpretations of usability and its costs and benefits emerged inside the organization in great detail. In addition, future research is needed related to usability-cost benefit analysis, particularly when carried out in professional manner, which was not the case in this case organization.

\section{References}

1. Artman, H.: Procurer usability requirements negotiations in contract development. In: Bertelsen, O.W., Bødker, S., Kuutti, K. (eds.) Proc. 2nd Nordic Conference on HumanComputer Interaction, pp. 61-70. ACM Press, New York (2002)

2. Asaro, P.: Transforming Society by Transforming Technology: the science and politics of participatory design. Accounting, Management and Information Technologies 10(4), 257$290(2000)$

3. Aucella, A.: Ensuring Success with Usability Engineering. Interactions (May + June 1922, 1997)

4. Bevan, N.: Cost Benefit Analysis version 1.1. Trial Usability Maturity Process. Serco Usability Services (2000)

5. Bias, R., Mayhew, D.: Cost-Justifying Usability. Academic Press, Boston (1994)

6. Bias, R., Mayhew, D.: Cost-Justifying Usability, Second edn., An Update for the Internet Age. Academic Press, Boston (2005)

7. Bloomer, S., Croft, R.: Pitching Usability to Your Organization. Interactions (November + December 18-26, 1997)

8. Bulkeley, W.: Study finds hidden costs of computing. The Wall Street Journal, B4 (November 2, 1992)

9. Catarci, T., Matarazzo, G., Raiss, G.: Driving usability into the public administration: the Italian experience. International Journal of Human-Computer Studies 57, 121-138 (2002)

10. Denzin, N.K., Lincoln, Y.S.: Introduction: The Discipline and Practice of Qualitative Research. In: Denzin, N., Lincoln, Y. (eds.) Handbook of Qualitative Research, 2nd edn., Sage Publications Inc, Thousand Oaks (2000)

11. Donahue, G.: Usability and the Bottom Line. IEEE Software 18(1), 31-37 (2001)

12. Ehrlich, K., Rohn, J.: Cost Justification of Usability Engineering: A Vendor's Perspective. In: Bias, R., Mayhew, D. (eds.) Cost-Justifying Usability, pp. 73-110. Academic Press, London (1994)

13. Fellenz, C.B.: Introducing Usability into Smaller Organizations. Interactions 4(5), 29-33 (1997)

14. Greenbaum, J., Kyng, M.(eds.): Design at Work. Cooperative Design of Computer Systems. Lawrence Erlbaum Associates, New Jersey (1991)

15. Grudin, J.: Systematic Sources of Suboptimal Interface Design in Large Product Development Organizations. Human-Computer Interaction 6(2), 147-196 (1991) 
16. Iivari, N.: Discourses on 'culture' and 'usability work' in software product development. Acta Universitatis Ouluensis, Series A, Scientiae rerum naturalium 457 (2006)

17. ISO 13407. Human-centered design processes for interactive systems. International standard (1999)

18. ISO/IEC 9126-1. Software Engineering, Product quality, Part 1: Quality model. International Standard (2001)

19. Karat, C.-M.: A Business Case Approach to Usability Cost Justification. In: Bias, R., Mayhew, D. (eds.) Cost-Justifying Usability, pp. 45-70. Academic Press, London (1994)

20. Klein, H.K., Myers, M.D.: A Set of Principles for Conducting and Evaluating Interpretive Field Studies in Information Systems. MIS Quarterly 23(1), 67-94 (1999)

21. Mayhew, D.: Strategic Development of Usability Engineering Function. Interactions 6(5), 27-34 (1999)

22. Mayhew, D.: The usability engineering lifecycle: a practitioner's handbook for user interface design. Morgan Kaufmann Publishers, San Francisco (1999)

23. Mayhew, D., Mantei, M.: A Basic Framework for Cost-Justifying Usability Engineering. In: Bias, R., Mayhew, D. (eds.) Cost-Justifying Usability, pp. 9-43. Academic Press, London (1994)

24. Nielsen, J.: Usability engineering. Academic Press, Boston (1993)

25. Ohnemus, K.: Incorporating Human Factors in the System Development Life Cycle: Marketing and Management Approaches. In: IPCC96, pp. 46-53. IEEE, Los Alamitos (1996)

26. Rajanen, M.: Different Approaches to Usability Cost-Benefit Analysis. In: Remenyi, D., Brown, A. (eds.) Proc. ECITE 2006, pp. 391-397. Academic Press, Reading (2006)

27. Rosenbaum, S., Rohn, J.A., Humburg, J.: A Toolkit for Strategic Usability: Results from Workshops, Panels, and Surveys. In: Turner, T., Szwillus, G., Czerwinski, M., Paterno, F., Pemberton, S. (eds.) Proc. CHI 2000, pp. 337-344. ACM, New York (2000)

28. Rosson, M., Carroll, J.: Usability Engineering: Scenario-based Development of HumanComputer Interaction. Morgan-Kaufman, San Francisco (2002)

29. Spinuzzi, C.: A Scandinavian Challenge, a US Response: Methodological Assumptions in Scandinavian and US Prototyping Approaches. In: Haramundanis, K., Priestley, M. (eds.) Proc. 20th Annual International Conference on Computer Documentation, pp. 208-215. ACM, New York (2002)

30. Tudor, L.: Human Factors: Does Your Management Hear You? Interactions 5(1), 16-24 (1998)

31. Vredenburg, K., Mao, J., Smith, P.W., Casey, T.: A survey of user-centered design practice. In: Wixon, D. (ed.) Proc. of CHI'02, pp. 471-478. ACM, New York (2002) 